\title{
Effect of psoriasis activity on serum adiponectin and leptin levels
}

\author{
Anna Baran ${ }^{1}$, Iwona Flisiak¹, Jerzy Jaroszewicz², Magdalena Świderska² \\ ${ }^{1}$ Department of Dermatology and Venereology, Medical University of Bialystok, Bialystok, Poland \\ Head of the Department: Prof. Iwona Flisiak MD, PhD \\ 2Department of Infectious Diseases and Hepatology, Medical University of Bialystok, Bialystok, Poland \\ Head of the Department: Prof. Robert Flisiak MD, PhD
}

Postep Derm Alergol 2015; XXXII, 2: 101-106

DOI: $10.5114 /$ pdia.2014.40960

\begin{abstract}
Introduction: Psoriasis is an inflammatory and chronic skin disease associated with obesity, cardiovascular diseases, diabetes and metabolic syndrome. Adipokines, as bioactive substances secreted from adipose tissue, are involved in various metabolic diseases.

Aim: To investigate the association between psoriasis severity and serum adiponectin and leptin levels in patients with psoriasis.

Material and methods: Serum fasting adiponectin and leptin levels were examined by an enzyme-linked immunosorbent assay in 49 patients with relapse of plaque-type psoriasis and 16 healthy controls. The results were correlated with the Psoriasis Area and Severity Index (PASI), body mass index (BMI), several inflammatory markers, duration of the disease and present relapse.

Results: Serum adiponectin and leptin levels were significantly decreased in psoriatic patients in comparison to the control group. There were no correlations between the above measures and PASI scores, patients' age, duration of the disease, present relapse and hospitalization, neither between white blood cells or platelets counts. Serum adiponectin levels significantly correlated with C-reactive protein (CRP) levels. Adiponectin was negatively and leptin positively correlated to BMI at statistical significance. Multivariate analysis demonstrated a significant positive correlation between adiponectin and CRP or PASI concentrations as well as between BMI and leptin concentration. Conclusions: The data showed that serum adiponectin levels increase and serum leptin levels decrease with psoriasis severity. Leptin might be useful in assessing severity and the risk of complications of psoriasis. Moreover, these results confirmed the relationship between leptin, obesity and psoriasis.
\end{abstract}

Key words: psoriasis, adipokines, adiponectin, leptin, psoriasis severity.

\section{Introduction}

Psoriasis is a chronic inflammatory skin disease, affecting $1.5-3 \%$ of the world population. The pathogenesis of psoriasis is complex and depends on many factors, including genetic, neurogenic, hormonal or autoimmune ones [1-6]. Immunological disturbances with predominance of Th1 response and oversynthesis of proinflammatory cytokines especially in combination with genetic predisposition lead to a pathogenic vicious circle with the inception and maintenance of the chronic inflammation and abnormal epidermal proliferation [7]. In recent years clear links have been established between psoriasis and a number of diseases such as obesity, cardiovascular diseases, diabetes and metabolic syndrome [8-10]. Psoriasis has also been recognized as an independent risk factor for myocardial infarction, especially in young patients suffering from the severe form of the disease $[11,12]$. It was shown that metabolic syndrome occurs in $40 \%$ or even $65 \%$ of psoriatic patients $[1,13]$. Obesity, which is also one of the diagnostic criteria of metabolic syndrome, was demonstrated as an independent risk factor for developing psoriasis and even doubling the risk [14-16]. A chronic inflammatory process observed in psoriasis is additionally aggravated by the accompanying diseases, especially obesity. It is assumed that in both these conditions, similar pathways of immune disorders occur $[14,17]$. On the genetic basis, the most important susceptibility locus for psoriasis, HLA-

Address for correspondence: Anna Baran MD, PhD, Department of Dermatology and Venereology, Medical University of Bialystok, 14 Zurawia St, 15-540 Bialystok, Poland, phone/fax: +48 8574095 70, e-mail: aannabaran@wp.pl Received: 12.11.2013, accepted: 12.12.2013. 
CW6, is associated with obesity $[12,14]$. White adipose tissue, regarded actually as the largest endocrine organ, has the ability to synthesize and secrete peptides such as adipokines which have an impact on many physiological functions. These bioactive substances play a role in regulating homeostasis, nutrition, blood pressure, carbohydrate and lipid metabolism, coagulation, insulin resistance, atherosclerosis and inflammatory or immunological processes $[18,19]$. Adipokines participate in the development of certain diseases such as diabetes, obesity, metabolic syndrome, systemic sclerosis and psoriasis [12]. Adiponectin is clearly associated with obesity and metabolic syndrome, which in turn may contribute to the increased risk of psoriasis and its exacerbation [20-22]. Decreased adiponectin levels are found in obesity, insulin resistance, type 2 diabetes, dyslipidemia and coronary heart diseases (CVD) [15, 23, 24]. Hypoadiponectinemia thus may be an independent risk factor for hypertension and type 2 diabetes [14, 22]. It was shown that the gene encoding adiponectin is located in a region most likely to metabolic syndrome, type 2 diabetes and CVD [14]. These diseases strictly correlate with psoriasis. It is assumed that adiponectin may prevent the development of psoriatic lesions inter alia by inhibiting the excessive inflammatory process [25]. It is assumed that leptin acts contrary to adiponectin in numerous physiological functions. Hyperleptinemia is observed in obesity, type 2 diabetes, metabolic syndrome, chronic renal failure and atherosclerosis [15]. In patients with coronary artery disease, leptin is a new and promising predictive factor of the occurrence of cardiovascular events in the future [26]. Postulated leptin's impact on coexistence of hypertension with severe obesity may have a more negative impact on the course of psoriasis [7]. Leptin also exerts an influence on the immune system. It stimulates a Th1 immune response and inhibits Th2 response [27]. This may confirm the participation of leptin in the pathogenesis of many autoimmune inflammatory processes, such as diabetes, rheumatoid arthritis and psoriasis $[27,28]$. It has been suggested that leptin may be a marker of severity of psoriasis [29]. The actual role of adipokines in the pathogenesis of psoriasis is not fully understood. Data from clinical studies are insufficient and inconsistent.

\section{Aim}

The aim of this study was to evaluate adiponectin and leptin serum concentrations in patients with psoriasis with respect to their association with psoriasis severity and obesity as well as inflammatory markers and clinical picture of the disease.

\section{Material and methods \\ Patients}

Fasting serum samples were obtained from 49 patients (15 females and 34 males) with exacerbation of chronic plaque-type psoriasis, aged between 19 and 84 years (mean: $48.6 \pm 2.4$ ). The disease duration varied from 7 months to 55 years (mean: $17.4 \pm 1.8$ ) and duration of the present relapse from 2 weeks to 2 years (mean: $4.4 \pm 0.9$ ). Patients with other forms of psoriasis and any other chronic inflammatory or metabolic diseases were excluded from the study. Blood samples were collected before starting any treatment. Adiponectin and leptin serum concentrations were analyzed with respect to the Psoriasis Area and Severity Index (PASI) score and normal values collected from 16 age, sex and body mass index (BMI)-matched healthy controls. Informed consent was obtained from each subject before enrollment. The study was approved by the Bioethical Committee of Medical University of Bialystok.

\section{PASI score}

Psoriasis area and severity index was evaluated by the same investigator (A.B.) in all patients according to rules proposed by Fredriksson and Pettersson as described previously $[23,30]$. The PASI score below 10 defined psoriasis as mild, between 10 and 20 as moderate and above 20 as severe.

\section{Samples collection}

Venous blood samples were collected using vacutainer tubes and allowed to clot for 30 min before centrifugation for $15 \mathrm{~min}$ at $1000 \mathrm{~g}$, then serum was divided for further measurements and stored at $-20^{\circ} \mathrm{C}$.

\section{Measurement of adiponectin and leptin}

Thawed samples were assayed in duplicate with enzyme-linked immunosorbent assay (ELISA) according to the manufacturer's instructions. Adiponectin and leptin serum levels were determined by Quantikine ${ }^{\varpi}$ Human Adiponectin and Leptin Immunoassays (R\&D Systems, Inc. Minneapolis, USA) with sensitivity of $0.246 \mathrm{ng} / \mathrm{ml}$ and $7.8 \mathrm{pg} / \mathrm{ml}$, respectively. Optical density was read with a microtitre plate photometer at $450 \mathrm{~nm}$. The concentration was determined by interpolation from a standard curve prepared with standard samples supplied by the manufacturer. Adiponectin serum concentrations were expressed in $\mathrm{ng} / \mathrm{ml}$, whereas leptin in $\mathrm{pg} / \mathrm{ml}$.

\section{Statistical analysis}

Values were expressed as the mean and standard error $( \pm$ SE). The statistical comparison among groups was calculated by a two-tailed Student's t-test. Correlations were performed using Shapiro-Wilk test, Mann-Whitney Rank Sum test and Spearman's rank-order correlation coefficient for non-parametric data. Logistic regression was used for multivariate analysis of associations. Value of $p<0.05$ was considered as statistically significant. 


\section{Results}

Of the 49 patients studied, 11 (22.5\%) had mild psoriasis (PASI < 10), 23 persons $(46.9 \%)$ moderate (PASI 10-20) and 15 patients (30.6\%) were diagnosed with the severe form (PASI > 20). The mean concentrations of adiponectin $(11648 \pm 1338 \mathrm{ng} / \mathrm{ml})$ in sera of psoriatic patients were over 1.5 times lower than in healthy controls (17644 $\pm 1659 \mathrm{ng} / \mathrm{ml}$ ) and the mean values of leptin (33314 \pm 6937 $\mathrm{pg} / \mathrm{ml}$ ) was 2.4 times lower than in controls (33314 \pm 6937 $\mathrm{pg} / \mathrm{ml}$ ) and these differences were statistically significant (Table 1). For none of the investigated adipokines, a significant correlation with PASI was observed.

Assessing the relationship between concentrations of adipokines and basic laboratory indices of inflammation activity, only the adiponectin serum level showed a positive correlation with the sedimentation rate (SR) and C-reactive protein (CRP) levels. Adiponectin was negatively and leptin positively correlated to BMI at statistical significance (Table 2). Multivariate analysis demonstrated a significant positive correlation between the adiponectin
Table 1. Serum adiponectin and leptin concentrations in patients with psoriasis and controls

\begin{tabular}{lcc}
\hline Variable & Adiponectin $[\mathrm{ng} / \mathrm{ml}]$ & Leptin $[\mathrm{pg} / \mathrm{ml}]$ \\
\hline Psoriasis $(n=49)$ & $11648 \pm 1338$ & $13798 \pm 2472$ \\
\hline Controls $(n=16)$ & $17644 \pm 1659$ & $33314 \pm 6937$ \\
\hline Value of $p$ & 0.004 & 0.002 \\
\hline
\end{tabular}

Results presented as $x \pm S E$.

level and CRP or PASI and negative with BMI while for leptin a significant positive correlation with BMI (Table 3).

Despite the lack of significance, serum adiponectin concentrations in patients with psoriasis increased with disease activity expressed by thePASI score (Figure 1), which was particularly evident in patients with PASI score above 20 . The mean adiponectin levels in patients with PASI score < $10(10367 \pm 2375 \mathrm{ng} / \mathrm{ml})$ and in patients with PASI score between 10 and $20(8966 \pm 1250 \mathrm{ng} / \mathrm{ml})$ were significantly lower than in healthy controls (17644 $\pm 1659 \mathrm{ng} / \mathrm{ml}$ ) (Tables 4, 5).

Table 2. Mean ( $\pm \mathrm{SE}$ ) values and correlations (R-values) between age, duration of the disease, present relapse, basic laboratory inflammatory measures, BMI and PASI score vs. serum adiponectin and leptin concentrations

\begin{tabular}{|c|c|c|c|c|c|c|c|}
\hline \multirow[t]{2}{*}{ Parameter } & \multirow[t]{2}{*}{$x \pm S E$} & \multicolumn{3}{|c|}{ Adiponectin } & \multicolumn{3}{|c|}{ Leptin } \\
\hline & & $R$ & $t$ & $p$ & $R$ & $t$ & $p$ \\
\hline $\mathrm{SR}[\mathrm{mm} / \mathrm{h}]$ & $21.4 \pm 2.7$ & 0.307 & 2.160 & $0.036^{*}$ & -0.156 & -1.085 & 0.283 \\
\hline $\mathrm{CRP}[\mathrm{mg} / \mathrm{l}]$ & $18.9 \pm 7.2$ & 0.326 & 2.313 & $0.025^{*}$ & -0.064 & -0.439 & 0.663 \\
\hline WBC $\left[\times 10^{3} / \mathrm{ml}\right]$ & $7.7 \pm 0.3$ & 0.105 & 0.711 & 0.481 & -0.102 & -0.703 & 0.486 \\
\hline $\mathrm{PLT}\left[\times 10^{3} / \mathrm{ml}\right]$ & $215.6 \pm 9.5$ & 0.247 & 1.713 & 0.094 & -0.161 & -1.118 & 0.269 \\
\hline Age [years] & $48.6 \pm 2.4$ & 0.265 & 1.844 & 0.072 & 0.005 & 0.037 & 0.971 \\
\hline Lenght of hospitalization [days] & $11.9 \pm 0.6$ & -0.042 & -0.285 & 0.777 & -0.206 & -1.446 & 0.155 \\
\hline Relapse duration [months] & $4.4 \pm 0.9$ & -0.033 & -0.221 & 0.826 & 0.259 & 1.836 & 0.073 \\
\hline Disease duration [years] & $17.4 \pm 1.8$ & 0.111 & 0.746 & 0.459 & 0.117 & 0.811 & 0.422 \\
\hline $\mathrm{BMI}\left[\mathrm{kg} / \mathrm{m}^{2}\right]$ & 28. \pm 1.2 & -0.581 & -4.783 & $<0.001^{\star}$ & 0.657 & 5.971 & $<0.001^{\star}$ \\
\hline PASI [score] & $16.5 \pm 1.1$ & 0.232 & 1.600 & 0.117 & -0.144 & -0.996 & 0.325 \\
\hline
\end{tabular}

*Statistically significant correlation $(p<0.05)$.

Table 3. Summary of multivariate regression analysis of dependent variable regression (the variable regression analysis was adopted with $p<0.15$ in univariate analysis)

\begin{tabular}{|c|c|c|c|c|}
\hline \multirow[t]{2}{*}{ Parameter } & \multicolumn{2}{|c|}{ Adiponectin } & \multicolumn{2}{|c|}{ Leptin } \\
\hline & $t$ & $p$ & $t$ & $p$ \\
\hline $\mathrm{SR}[\mathrm{mm} / \mathrm{h}]$ & -0.45 & 0.652 & - & - \\
\hline $\mathrm{CRP}[\mathrm{mg} / \mathrm{l}]$ & 2.46 & $0.018^{*}$ & - & - \\
\hline $\operatorname{PLT}\left[\times 10^{3} / \mathrm{ml}\right]$ & 1.89 & 0.068 & - & - \\
\hline Age [years] & 1.75 & 0.088 & - & - \\
\hline PASI [score] & 2.03 & $0.049^{\star}$ & - & - \\
\hline Relapse duration [months] & - & - & 1.85 & 0.071 \\
\hline $\mathrm{BMI}\left[\mathrm{kg} / \mathrm{m}^{2}\right]$ & -2.34 & $0.005^{\star}$ & 3.15 & $0.003^{*}$ \\
\hline
\end{tabular}

*Statistically significant correlation $(p<0.05)$. 
Table 4. Comparison of serum adiponectin and leptin concentrations ( $p$-values) in psoriatic patients between three groups $(<10,10-20,>20)$ depending on PASI using the Mann-Whitney test

\begin{tabular}{lccc}
\hline Parameter & \multicolumn{3}{c}{ PASI } \\
\cline { 2 - 4 } & $<$ 10 vs. 10-20 & < 10 vs. $>$ 20 & 10-20 vs. $>20$ \\
\hline Adiponectin & 0.755 & 0.357 & 0.133 \\
\hline Leptin & 0.744 & 0.384 & 0.202 \\
\hline
\end{tabular}

The mean serum leptin concentrations in patients with psoriasis decreased in accordance with disease activity demonstrated by the PASI score (Figure 2). The mean leptin levels in patients with PASI between 10 and $20(15008 \pm 3258 \mathrm{pg} / \mathrm{ml})$ and > $20(9216 \pm 2701 \mathrm{pg} / \mathrm{ml})$ were significantly lower in comparison with the controls (33314 $\pm 6937 \mathrm{pg} / \mathrm{ml}$ ) (Table 5).

\section{Discussion}

In this study, we demonstrated that measurement of adipokines can be useful for assessment of psoriasis severity and its relationships with other comorbidities. Mean serum adiponectin concentrations as reported in the literature in patients with psoriasis varied from 8374

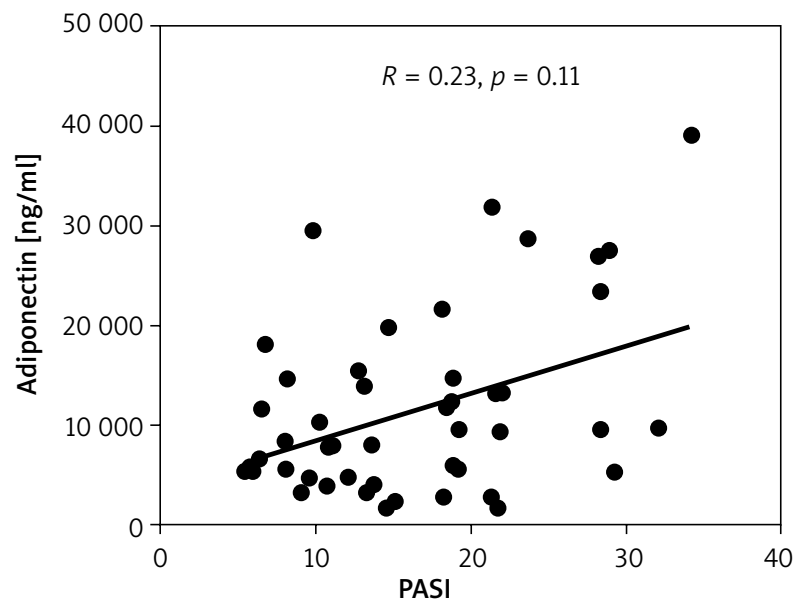

Figure 1. Correlation between serum adiponectin concentrations and PASI score $\mathrm{ng} / \mathrm{ml}$ to $18520 \mathrm{ng} / \mathrm{ml}$. Mean values reported in our study were located in the upper range of this interval: 11648 $\pm 1338 \mathrm{ng} / \mathrm{ml}$. The mean adiponectin concentrations in the control group were higher (17644 $\pm 1659 \mathrm{ng} / \mathrm{ml}) \mathrm{com}$ pared with other studies (6122-9471 ng/ml) [29, 31-33]. These differences can be explained by high sensitivity of the assay used in our study.

Previously published data on adiponectin levels in patients with psoriasis are inconsistent. Most of the studies including our results show significantly decreased serum adiponectin concentrations in psoriasis [21, 22, 31, 34]. It is assumed that adiponectin, beyond the role in regulation of metabolic processes, has also an anti-inflammatory activity. It was shown that tumor necrosis factor $\alpha$ (TNF- $\alpha$ ) and interleukin-6 (IL-6) inhibit the synthesis of adiponectin by adipose tissue. Increased levels of proinflammatory cytokines in psoriatic patients, particularly IL-6, may be one of the causes leading to decreased production of adiponectin by the subcutaneous and visceral adipose tissue [22, 31].

However, there are some studies which have not reported any difference of adiponectin levels in psoriatic patients compared to normal [20, 21, 27, 32, 33], whereas in some other recently published studies, an increase of adiponectin levels has been reported $[17,35]$.

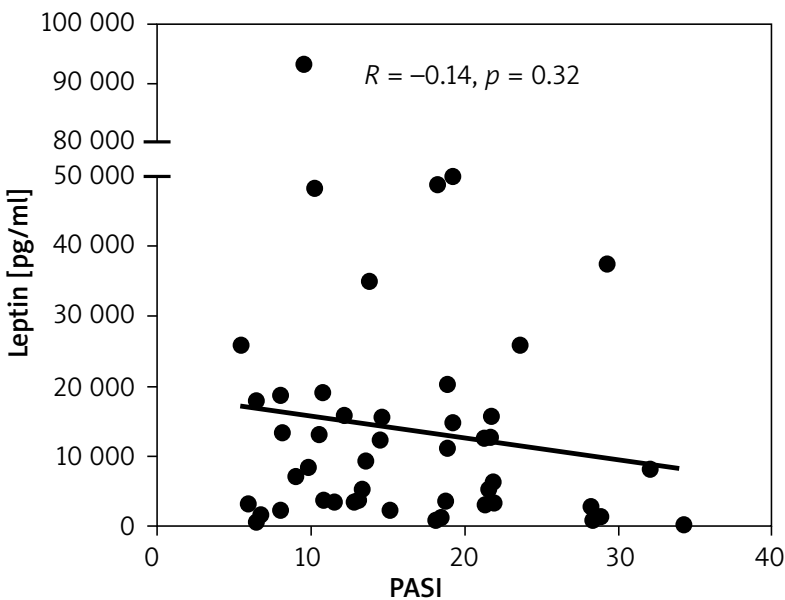

Figure 2. Correlation between serum leptin concentrations and PASI score

Table 5. Comparison of mean \pm SE concentrations of serum adiponectin and leptin in controls vs. psoriatic patients depending on PASI score

\begin{tabular}{|c|c|c|c|c|}
\hline \multirow[t]{2}{*}{ Parameter } & \multirow[t]{2}{*}{ Controls } & \multicolumn{3}{|c|}{ Psoriatic patients } \\
\hline & & $<10(n=11)$ & $10-20(n=23)$ & $>20(n=15)$ \\
\hline \multirow[t]{2}{*}{ Adiponectin [ng/ml] } & $17644 \pm 1659$ & $10367 \pm 2375$ & $8966 \pm 1250$ & $14713 \pm 2904$ \\
\hline & & $0.011^{*}$ & $0.0003^{*}$ & 0.477 \\
\hline \multirow[t]{2}{*}{ Leptin [pg/ml] } & $33314 \pm 6937$ & $17516 \pm 7962$ & $15008 \pm 3258$ & $9216 \pm 2701$ \\
\hline & & 0.050 & $0.020^{*}$ & $0.001^{*}$ \\
\hline
\end{tabular}

*Statistically significant correlation ( $p<0.05)$ vs. controls (Mann-Whitney test). 
Our study demonstrated a significant negative correlation between $\mathrm{BMI}$ and adiponectin levels, what was consistent with the results of others [17, 21, 31, 33]. Thus, data indicate the need to consider the nutritional state of patients with psoriasis when assessing clinical studies on adipokines. Decreased levels of adiponectin in patients with obesity may be due to its higher risk of development of numerous chronic diseases accompanied by inflammation. Kaur et al. [20] confirmed the aggravation of generalized inflammation and oxidative stress, denoted by the glutathione redox ratio (GSH) in obese psoriatic patients in comparison to patients with normal body weight. Carrascosa et al. [36] indicate that obesity increases the risk of adverse effects of systemic treatment of psoriasis and may lead to augmentation of biological agents' dosages in order to avoid a decrease inefficacy of these drugs.

We were not able to show any statistically significant correlation between serum adiponectin levels and PASI score, which is consistent with the results of other authors [17, 21, 37].

Our data showed that serum adiponectin levels increase with psoriasis severity defined as the PASI score. However, the significant correlation with PASI, CRP and BMI (negative) in multivariate analysis was confirmed. Therefore, it must be assumed that serum adiponectin levels in psoriatic patients are dependent not only on the disease activity, but also on several systemic immune and inflammatory processes, which undoubtedly affect the body's metabolic state associated mainly with the body weight. In our study, we found overweight in $36.7 \%$ and obesity in $32.6 \%$ of patients with psoriasis. These results are consistent with the data from the literature and confirm a positive correlation between psoriasis and obesity and its possible impact on the reduction of adiponectin levels [15, 20, 31].

In the present study, there were no correlations between adiponectin levels and patients' age, duration of the disease, present relapse and hospitalization. We could not find in the literature data such associations beside one positive correlation between adiponectinemia and age of the psoriatic patients, what highlights a unique value of our study [21].

There are only few investigations evaluating the association between adiponectin and inflammatory markers $[21,38]$. In the presented study, the adiponectin serum level showed a positive correlation with SR and CRP levels. Associations between adiponectinemia and basic laboratory measures of inflammatory activity indicate possible importance in the course of psoriasis, but knowledge in this field is still insufficient.

Mean serum leptin levels in psoriatic patients as reported in the literature varied from $14250 \mathrm{ng} / \mathrm{ml}$ to 26390 $\mathrm{ng} / \mathrm{ml}$. The mean leptin concentration in our study was slightly lower (13798 $\pm 2472 \mathrm{pg} / \mathrm{ml}$ ), but similar. Data from other papers on leptin levels in psoriatic patients are more uniform and consistent in comparison to adiponec- tin, but also few and contradictory with our results. Only two studies have not reported any difference in leptin levels in psoriatic patients [17, 27]. The majority of authors have demonstrated a significant increase in leptin levels in psoriasis [33-35, 39-41].

In this study the mean serum leptin concentration in patients with psoriasis was significantly lower than in the controls. The divergent behavior of leptin levels in comparison to few other studies may be due to genetic and nutritional differences affecting the development of obesity. As demonstrated in our study there is a clear significant correlation between leptin and BMI, confirmed by both univariate and multivariate analysis. This corroborates the link between leptin, psoriasis and obesity, expressed as BMI found in other papers [12, 17, 21, 27, 31, 41, 42]. The divergence of various investigations indicates existence of other unknown aspects related to the role of leptin in the pathogenesis of psoriasis. We should also take into consideration some possible methodological variations or differences in leptin levels between different populations [29].

In discussed studies, serum leptin levels decreased with psoriasis severity, expressed as PASI score but without statistical significance. However, data concerning this relationship are very limited [17, 29, 40, 43]. The association between serum leptin levels and inflammatory markers (CRP, IL-6) was assessed probably once by Kaur et al. [21]. Our study also showed no significant association with white blood cell count (WBC), platelet count (PLT), sedimentation rate (SR) and CRP. These results seem to contradict previous assumptions that leptin itself may be an acute phase protein derived from adipose tissue [44].

We were not able to present any significant correlations between serum leptin levels and patients' age, duration of the disease, present relapse and hospitalization. In the literature there are few and inconsistent data on these issues [12, 29, 40, 41].

\section{Conclusions}

Results of our study demonstrated an increase in adiponectin and decrease in leptin serum levels with psoriasis severity. Serum leptin measurement might be useful in assessing the severity and risk of complications of psoriasis. Additionally presented data confirmed the relationship between leptin, obesity and psoriasis.

\section{Conflict of interest}

The authors declare no conflict of interest.

\section{References}

1. Gisondi P, Tessari G, Conti A, et al. Prevalence of metabolic syndrome in patients with psoriasis: a hospital-based case-control study. Br J Dermatol 2007; 157: 68-73.

2. Green L. An overview and update of psoriasis. Nurs Stand 2011; 25: 47-55. 
3. Gudjonsson J, Elder J. Psoriasis: epidemiology. Clin Dermatol 2007; 25: 535-46.

4. Liu Y, Krueger J, Bowcock A. Psoriasis: genetic associations and immune system changes. Genes Immun 2007; 8: 1-12.

5. Ryan S. Psoriasis: characteristics, psychosocial effects and treatment options. Br J Nurs 2010; 19: 820, 822-5.

6. Nedoszytko B, Sokołowska-Wojdyło M, Ruckemann-Dziurdzińska K, et al. Chemokines and cytokines network in the pathogenesis of the inflammatory skin diseases: atopic dermatitis, psoriasis and skin mastocytosis. Postep Derm Alergol 2014; 31: 84-91.

7. Chomiczewska-Skóra D, Trznadel-Grodzka E, Rotsztejn H. Psoriasis as a disease associated with the immune system disorders. Centr Eur J Immunol 2013; 38: 129-33.

8. Farley E, Menter A. Psoriasis: comorbidities and associations. G Ital Dermatol Veneorol 2011; 146: 9-15.

9. Kim N, Thrash B, Menter A. Comorbidities in psoriasis patients. Semin Cutan Med Surg 2010; 29: 10-5.

10. Wielowieyska-Szybińska D, Wojas-Pelc A. Psoriasis: course of disease and treatment. Postep Derm Alergol 2012; 29: 118-22.

11. Ahlehoff O, Gislason GH, Lindhardsen J, et al. Psoriasis carries an increased risk of venous thromboembolism: a Danish nationwide cohort study. PLoS One 2011; 25: e18125.

12. Chen YJ, Wu CY, Shen JL, et al. Psoriasis independently as sociated with hyperleptinemia contributing to metabolic syndrome. Arch Dermatol 2008; 144:1571-5.

13. Love TJ, Qureshi AA, Karlson EW, et al. Prevalence of metabolic syndrome in psoriasis. Results from the national health and nutrition examination survey, 2003-2006. Arch Dermatol 2011; 147: 419-24.

14. Gerdes S, Rostami-Yazdi M, Mrowietz U. Adipokines and psoriasis. Exp Dermatol 2011; 20: 81-7.

15. Herron MD, Hinckley M, Hoffman MS, et al. The impact of obesity and smoking on psoriasis presentation and management. Arch Dermatol 2005; 141: 1527-34.

16. Naldi L, Chatenoud L, Linder D, et al. Cigarette smoking, body mass index, and stressfull life events as risk factors for psoriasis: results from an Italian case-control study. J Invest Dermatol 2005; 125: 61-7.

17. Gerdes S, Osadtschy S, Rostami-Yazdi M, et al. Leptin, adiponectin, visfatin and retinol-binding protein-4- mediators of comorbidities in patients with psoriasis? Exp Dermato 2012; 21: 43-7.

18. Ouchi N, Parker JL, Lugus JJ, et al. Adipokines in inflammation and metabolic disease. Nat Rev Immunol 2011; 11: 85-97.

19. Wozniak SE, Gee LL, Wachtel MS, et al. Adipose tissue: the new endocrine organ? A review article. Dig Dis Sci 2009; 54: 1847-56.

20. Kaur S, Zilmer K, Kairane C, et al. Clear differences in adiponectin level and glutathione redox status revealed in obese and normal-weight patients with psoriasis. Br J Dermatol 2008; 159: 1364-7.

21. Kaur S, Zilmer K, Leping V, et al. The levels of adiponectin and leptin and their relation to other markers of cardiovascular risk in patients with psoriasis. J Eur Acad Dermatol Venereol 2011; 25: 1328-33.

22. Shibata S, Tada Y, Hau C, et al. Adiponectin as an anti-inflammatory factor in the pathogenesis of psoriasis: induction of elevated serum adiponectin levels following therapy. Br J Dermatol 2011; 164: 667-70.

23. Flisiak I, Zaniewski P, Rogalska M, et al. Effect of psoriasis activity on VEGF and its soluble receptors concentrations in serum and plaque scales. Cytokine 2010; 52: 225-9.

24. Raucci R, Rusolo F, Sharma A, et al. Functional and structural features of adipokine family. Cytokine 2013; 61: 1-14.
25. Ouchi N, Walsh K. Adiponectin as an anti-inflammatory factor. Clin Chim Acta 2007; 380: 24-30.

26. Koerner A, Kratzsch J, Kiess W. Adipocytokines: leptin-the classical, resistin-the controversial, adiponectin-the promising, and more to come. Best Pract Res Clin Endocrinol Metab 2005; 19: 525-46.

27. Johnston A, Arnadottir S, Gudjonsson JE, et al. Obesity in psoriasis: leptin and resistin as mediators of cutaneous inflammation. Br J Dermatol 2008; 159: 342-50.

28. Conde J, Scotece M, Gómez R, et al. At the crossroad between immunity and metabolism: focus on leptin. Expert Rev Clin Immunol 2010; 6: 801-8.

29. Cerman AA, Bozkurt S, Sav A, et al. Serum leptin levels, skin leptin and leptin receptor expression in psoriasis. Br J Dermatol 2008; 159: 820-6.

30. Fredriksson T, Pettersson U. Severe psoriasis - oral therapy with a new retinoid. Dermatologica 1978; 157: 238-44.

31. Coimbra S, Oliveira H, Reis F, et al. Circulating adipokine levels in Portuguese patients with psoriasis vulgaris according to body mass index, severity and therapy. J Eur Acad Dermatol Venereol 2010; 24: 1386-94.

32. Janusz I, Lewandowski K, Lukamowicz J, et al. Assessment of insulin resistance and adiponectin concentration in patients with psoriasis vulgaris. Postep Derm Alergol 2010; 27: 451-5.

33. Nakajima H, Nakajima K, Tarutani M, et al. Kinetics of circulating cytokines and adipokines in psoriasis patients. Arch Dermatol Res 2011; 303: 451-5.

34. Stępień M, Wlazeł RN, Paradowski M, et al. Serum concentrations of adiponectin, leptin, resistin, ghrelin and insulin and their association with obesity indices in obese normoand hypertensive patients - pilot study. Arch Med Sci 2012; 8: 431-6.

35. Ozdemir M, Yüksel M, Gökbel H, et al. Serum leptin, adiponectin, resistin and ghrelin levels in psoriatic patients treated with cyclosporine. J Dermatol 2012; 39: 443-8.

36. Carrascosa JM, Rocamora V, Fernandez-Torres RM, et al. Obesity and psoriasis: inflammatory nature of obesity, relationship between psoriasis and obesity, and therapeutic implications. Actas Dermosifiliogr 2014; 105: 31-44.

37. Shibata S, Saeki H, Tada Y, et al. Serum high molecular weight adiponectin levels are decreased in psoriasis patients. J Dermatol Sci 2009; 55: 62-3.

38. Peters MJ, Watt P, Cherry L, et al. Lack of effect of TNFalpha blockade on circulating adiponectin levels in patients with autoimmune disease results from two independent prospective studies. Ann Rheum Dis 2010; 69: 1687-90.

39. Abdel Hay RM, Rashed LA. Association between the leptin gene $2548 \mathrm{G} / \mathrm{A}$ polymorphism, the plasma leptin and the metabolic syndrome with psoriasis. Exp Dermatol 2011; 20: 715-9.

40. Nakajima H, Nakajima K, Nagano Y, et al. Circulating level of chemerin is upregulated in psoriasis. J Dermatol Sci 2010; 60: 45-7.

41. Wang Y, Chen J, Zhao Y, et al. Psoriasis is associated with increased levels of serum leptin. Br J Dermatol 2008; 158: 1134-5.

42. Kawashima K, Torii K, Furuhashi T, et al. Phototherapy reduces serum resistin levels in psoriasis patients. Photodermatol Photoimmunol Photomed 2011; 27: 152-5.

43. Takahashi H, Tsuji H, Takahashi I, et al. Plasma adiponectin and leptin levels in Japanese patients with psoriasis. $\mathrm{Br}$ J Dermatol 2008; 159: 1207-8.

44. Bik W. The relationship between secretion of adipokines or insulin resistance and association of selected genes' polymorphisms of adiponectin and resistinin obesity. Post N Med 2009: 12: 912-80. 